\title{
A prostate cancer vaccine comprising whole cells secreting IL-7, effective against subcutaneous challenge, requires local GM-CSF for intra-prostatic efficacy
}

\author{
Caroline Schroten-Loef • Corrina M. A. de Ridder • \\ Suzanne Reneman • Marije Crezee • Angus Dalgleish • \\ Stephen M. Todryk $\cdot$ Chris H. Bangma $\cdot$ Robert Kraaij
}

Received: 23 May 2008 / Accepted: 1 July 2008 / Published online: 19 July 2008

(C) The Author(s) 2008

\begin{abstract}
A panel of cytokine-secreting RM-9 prostate cancer cells were tested as whole cell vaccines to determine their capacity to evoke an anti-prostate cancer immune response. In our model, vaccines secreting mGM-CSF or mIL-7 resulted in the highest increase in circulating T lymphocytes after vaccination, prolonged survival and, in a proportion of animals, tumor-free survival. Anti-tumor effects were more evident after a subcutaneous RM-9 challenge than after an intraprostatic challenge. However, when the RM-9/mGM-CSF cell line was used as intraprostatic tumor challenge, protection after RM-9/mIL-7 vaccination was restored.
\end{abstract}

Keywords Immunotherapy - Whole cell vaccine · Cytokines $\cdot$ Prostate cancer $\cdot$ MPR-model

\section{Introduction}

Prostate cancer is currently the most commonly diagnosed non-cutaneous malignancy in American and European men. Each year, about 600,000 new cases are diagnosed and

C. Schroten-Loef · C. M. A. de Ridder · S. Reneman · M. Crezee ·

C. H. Bangma $\cdot$ R. Kraaij $(\square)$

Erasmus MC, Department of Urology,

Josephine Nefkens Institute, Room Be355A,

P.O. Box 2040, 3000, CA Rotterdam, The Netherlands

e-mail: r.kraaij@erasmusmc.nl

\author{
A. Dalgleish \\ Department of Oncology, \\ St. George's University of London, London, UK \\ S. M. Todryk \\ School of Applied Sciences, \\ University of Northumbria, Newcastle-upon-Tyne, UK
}

about 200,000 men die worldwide, turning prostate cancer into a major public health problem [11]. Treatment of early stage (localized) prostate cancer may involve radical prostatectomy, active surveillance, radiation therapy and hormonal therapy. In case cancer has spread beyond the prostate, treatment options are limited. Palliative treatment for metastized prostate cancer is mainly focused on extending life and relief of symptoms. Therefore, new therapeutic modalities that specifically eradicate metastatic disease are needed.

The theoretical concept of a specific immune response against cancer is quite old and dates back to the nineteenth century $[18,37]$. In practice it has been proven very difficult to use immunotherapy against cancer. Tumors appear to be poorly immunogenic and often escape the hosts' immune response because they may lack both major histocompatibility complex (MHC) and co-stimulatory molecules [26]. Furthermore, regulatory $\mathrm{T}$ lymphocytes $\left(\mathrm{CD} 25^{+}\right)$are abundant in blood and tumor of cancer patients, which actively inhibits the proliferation of cancerspecific cytotoxic T lymphocytes [25, 33]. Over the years, several strategies have been explored that tried to overcome these escape mechanisms such as dendritic cell based immunotherapy [27], T lymphocyte based adoptive therapy [8], and vaccination therapy $[5,30,32]$. The use of autologous cancer cells as vaccines to augment tumor immunity has been explored, but the responses observed generally have been only partial and shorted-lived. Because of the poor immunogenicity of cancer cells, it is difficult to evoke the desired anti-cancer immune responses by vaccination only. Therefore, administration of cytokines could enhance the host's immune responses during vaccination.

Cytokines are secreted low molecular weight proteins that have a short half-life and serve as local mediators of cell-cell interactions. They include, among other molecules, 
the interferons (IFNs), the interleukins (ILs) and colonystimulating factors (CSFs). When cytokines are used as a medical drug, systemic administration at very high concentrations is necessary to achieve biologically meaningful concentrations at the target site. These high concentrations are associated with systemic toxicity, which limits their use and efficacy [14]. To bypass the toxic effects of systemic administration and to reach a biological meaningful concentration for inducing an optimal immune response, tumor cells were genetically modified to secrete cytokines locally. Such genetically modified tumor cells were rejected by the host with minimal side effects $[4,10,16,17,35]$, whereas unmodified cells were not rejected [17]. The observed antitumor responses involved recruitment of $\mathrm{CD}^{+} \mathrm{T}$ lymphocytes as well as recruitment of $\mathrm{CD}^{+} \mathrm{T}$ lymphocytes. Furthermore, several studies indicate that cytokine-secreting tumor cells increase systemic immunity as well, since mice vaccinated with cytokine-producing tumor cells reject a subsequent challenge of unmodified tumor cells, and in some cases, a preexisting tumor $[7,17,22]$. Since most of these studies have been carried out for different types of cancer models, cytokine-producing vaccines could also be of interest for rejection of prostate tumor cells.

In the present study, a panel of cytokine-producing whole cell vaccines (mIL-2, mIL-4, mIL-7, mGM-CSF and mCD40L) was constructed and analyzed for the induction of additional protection compared to a non-cytokine-producing cell vaccine against prostate cancer in an immunecompetent mouse prostate cancer model.

\section{Materials and methods}

Mouse prostate reconstitution model

The mouse prostate reconstitution model $[15,19]$ was kindly provided by Dr. T.C. Thompson. This model consists of several mouse prostate cancer cell lines that were derived from urogenital sinus cells from p53 knock-out $\mathrm{C} 57 \mathrm{bl} / 6$ mice. These cells were transformed by retroviral transduction with the ras- and myc-oncogenes.

The RM-9 cell line of this model was cultured in lowglucose Dulbecco's modified Eagles's medium (DMEM; Invitrogen, Breda, The Netherlands) supplemented 1:1 with Ham's F12 (Biowhittaker, Cambrex, Verviers, Belgium), $10 \%$ fetal calf serum (FCS; Hyclone, Etten-Leur, The Netherlands), $100 \mathrm{U} / \mathrm{ml}$ penicillin and $100 \mu \mathrm{g} / \mathrm{ml}$ streptomycin (Biowhittaker). Cells were grown at $37^{\circ} \mathrm{C}$ in a humidified atmosphere of $5 \% \mathrm{CO}_{2}$ in air and passaged twice a week.

Male C57bl/6 mice (6-12 weeks old) were purchased from Charles River Laboratories (St. Germain sur l'Arbresle, France), housed in individually ventilated cages (IVCs) and allowed to acclimatize for 1 week. Mouse chow and water were given ad libitum. Animal experiments were performed under the national Experiments on Animals Act that serves the implementation of "Guidelines on the protection of experimental animals" by the Council of Europe (1986), Directive 86/609/EC, and only after a positive recommendation by the Animal Experiments Committee. No alternatives (in relation to Replacement, Reduction or Refinement) were available.

Immunisation and tumor challenge strategy

The RM-9 cell line was retrovirally transduced to produce the immunostimulatory cytokines mIL-2, mIL-4, mIL-7, mGM-CSF and mCD40L [34]. Cytokine expression per one million of transfected cells per $24 \mathrm{~h}$ was determined to be $109 \mathrm{ng}$ (mIL-2), $233 \mathrm{ng}$ (mIL-4), $29 \mathrm{ng}$ (mIL-7) and $397 \mathrm{ng}$ (mGM-CSF). Expression of mCD40L was confirmed by FACS analysis.

Cells were harvested by trypsinisation, washed twice with PBS, resuspended in PBS at a density of $1 \times 10^{7}$ cells $/ \mathrm{ml}$, and $\gamma$-irradiated at $75 \mathrm{~Gy}$. Vaccination was performed once a week for three consecutive weeks by subcutaneous injection of $1 \times 10^{6} \gamma$-irradiated cells. One week after the final vaccination, a challenge was administered either orthotopically in the dorsolateral prostate $\left(5 \times 10^{4}\right.$ cells in $20 \mu \mathrm{l}$ PBS $)$ under anesthesia [29] or subcutaneously $\left(1 \times 10^{5}\right.$ cells in $100 \mu \mathrm{l}$ PBS). Orthotopic growth was monitored by transrectal ultrasonography under anesthesia with isofluraan $/ \mathrm{O}_{2}$ [21] and subcutaneous tumor growth was monitored by calliper measurements. Mice were killed when suffering from tumor burden, or when tumors exceeded $1,500 \mathrm{mg}$ for subcutaneous tumors or $1,000 \mathrm{mg}$ for orthotopic tumors.

Flow cytometry

Blood was collected in heparine-containing tubes (Sarstedt, Germany) through retro-orbital puncture under anesthesia with isofluraan $/ \mathrm{O}_{2}$, incubated for $1 \mathrm{~h}$ on ice with combinations of anti-mCD3-PE, anti-mCD4-PE-Cy5 and antimCD8-FITC, antibodies (BD Biosciences, Breda, The Netherlands), washed twice with PBS, disposed of erythrocytes with FACS ${ }^{\mathrm{TM}}$ lysis solution (BD Biosciences, Breda, The Netherlands), washed with PBS and fixed with $1 \%$ paraformaldehyde (Fluka Chemie GmBH, Buchs, Germany). FACS measurements were performed on a FACScan (BD Biosciences) and analyzed by CellQuest ${ }^{\mathrm{TM}}$ Pro, version 4.0.2 (BD Biosciences).

\section{Histology}

Tumors were snap-frozen in liquid nitrogen and stored at $-80^{\circ} \mathrm{C}$. Frozen sections $(4-5 \mu \mathrm{m})$ were fixed in acetone and stained with anti-mCD $4^{+}$, anti-mCD $8^{+}$, anti-mCD $11^{+}$ 
or anti-mCD19 ${ }^{+}$antibodies (BD Pharmingen). First antibody was detected using the anti-rat Ig HRP detection kit (BD Pharmingen) and counterstained with heamatoxilin and eosin. The sections were scored three times for infiltrated areas, which were represented as a percentage of the total vital tumor tissue.

\section{Statistical analyses}

Statistical analyses of survival and FACS data were performed with the Mann-Whitney $U$-test and the Student $T$ test, respectively, using SPSS version 11.0.1 (2001). Differences were considered significant when $P \leq 0.05$.

\section{Results}

Prolonged survival with IL-7 or GM-CSF-secreting vaccines

The panel of cytokine-producing RM-9 lines, together with the parental RM-9 and PBS as controls, were analyzed as vaccines. Seven groups of nine C57bl/6 mice were vaccinated and subcutaneously challenged with RM-9 cells (Fig. 1). The median survival after PBS vaccination was $13.1 \pm 1.9$ days. The RM-9 vaccinated group showed a significantly $(P=0.0004)$ prolonged survival of $34.0 \pm$ 8.2 days compared to the PBS control. The cytokineproducing vaccines were compared to the RM-9 control group. Survival after RM-9/mIL-2 and RM-9/mCD40L vaccination was comparable to survival of RM-9 vaccinated mice $(29.9 \pm 4.4$ days and $29.7 \pm 5.8$ days, respectively). Survival after RM-9/mIL-4 vaccination showed a decrease in life expectancy $(21.0 \pm 6.0$ days $)$. However, when mice were vaccinated with RM-9/mGM-CSF or RM9/mIL-7 also tumor-free survival was observed. Vaccination with RM-9/mGM-CSF resulted in the tumor-free survival of three out of nine mice and the median life-time of the non-survivors was $24.6 \pm 2.2$ days. RM-9/mIL-7 vaccination resulted in the survival of four out of nine mice, with and median life-time of non-surviving mice of $34.4 \pm 7.1$ days. Only the survival of the mice vaccinated with RM-9/mIL-7 was significant compared to the RM-9 control group $(P=0.025)$.

Increased $\mathrm{CD}^{+}$and $\mathrm{CD}^{+} \mathrm{T}$ lymphocyte responses after vaccination

To gain insight into the mechanisms of action of the different vaccines, $\mathrm{T}$ cell responses were analyzed. Blood was taken before and after vaccination (but before challenge administration), and $\mathrm{CD} 4^{+}$and $\mathrm{CD}^{+} \mathrm{T}$ lymphocyte population were analyzed (Fig. 2).

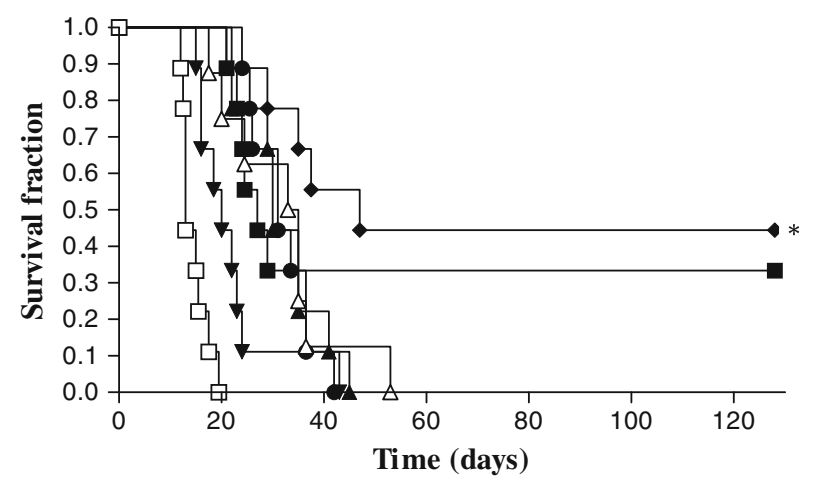

\begin{tabular}{|c|c|c|c|}
\hline Symbol & Vaccine & $\begin{array}{l}\text { Median survival } \pm \\
\sigma \operatorname{med}(\text { days })\end{array}$ & $\begin{array}{l}\text { Tumor-free } \\
\text { survival }\end{array}$ \\
\hline$\square$ & PBS & $13.1 \pm 1.9$ & $0 / 9$ \\
\hline$\triangle$ & RM-9 & $34.0 \pm 8.2$ & $0 / 8$ \\
\hline O & RM-9/mIL-2 & $29.9 \pm 4.4$ & $0 / 9$ \\
\hline$\nabla$ & RM-9/mIL-4 & $21.0 \pm 6.0$ & $0 / 9$ \\
\hline 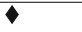 & RM-9/mIL-7 & $34.4 \pm 7.1$ & $4 / 9 *$ \\
\hline $\mathbf{\square}$ & RM-9/mGM-CSF & $24.6 \pm 2.2$ & $3 / 9$ \\
\hline$\Delta$ & RM-9/mCD40L & $29.7 \pm 5.8$ & $0 / 9$ \\
\hline
\end{tabular}

Fig. 1 Survival of vaccinated mice after subcutaneous challenge with RM-9 cells. Mice were vaccinated with $1 \times 10^{6} \gamma$-irradiated cells or PBS. Vaccines were administered once a week for three consecutive weeks, followed by a challenge of RM-9 cells in the fourth week. Tumor size was measured in time and survival determined $(* P<0.05$ compared to the RM-9 vaccinated group)

PBS and RM-9 vaccination did not induce (increase in circulating) $\mathrm{CD}^{+}$and $\mathrm{CD}^{+}$T-lymphocyte populations. However, all cytokine-producing vaccines induced significant increases in circulating $\mathrm{CD} 4^{+}$and $\mathrm{CD}^{+} \mathrm{T}$ lymphocyte populations. Moreover, the most effective vaccines, RM-9/ mGM-CSF and RM-9/mIL-7, that resulted in tumor-free survival, showed the highest $\mathrm{CD} 4^{+}$and $\mathrm{CD}^{+} \mathrm{T}$ lymphocyte counts. Furthermore, survivors and non-survivors were compared in $\mathrm{CD} 4^{+}$and $\mathrm{CD} 8^{+} \mathrm{T}$ lymphocyte responses. The survivors of the RM-9/mIL-7 vaccination group showed a significant lower $\mathrm{CD} 8^{+} \mathrm{T}$ lymphocyte count compared to the non-survivors $(P=0.031)$. Survivors of the RM-9/ mGM-CSF vaccination group showed a significant higher $\mathrm{CD}^{+} \mathrm{T}$ lymphocyte count $(P=0.046)$ (data not shown).

To determine whether systemic $\mathrm{CD}^{+}$and $\mathrm{CD}^{+}$ lymphocyte responses were reflected by the infiltrate of end-point tumor tissues, immune histochemistry was performed. Necrosis (HE-staining), T lymphocytes (CD4 ${ }^{+}$, $\left.\mathrm{CD}^{+}\right)$, B lymphocytes $\left(\mathrm{CD} 19^{+}\right)$as well as myelocytes and NK cells $\left(\mathrm{CD} 11 \mathrm{~b}^{+}\right)$were determined (Fig. 3 ). All vaccination groups showed to some degree necrotic areas in the tumor. The largest necrotic areas were observed in the groups vaccinated with RM-9/mIL-7, RM-9/mGM-CSF and RM-9/CD40L. 

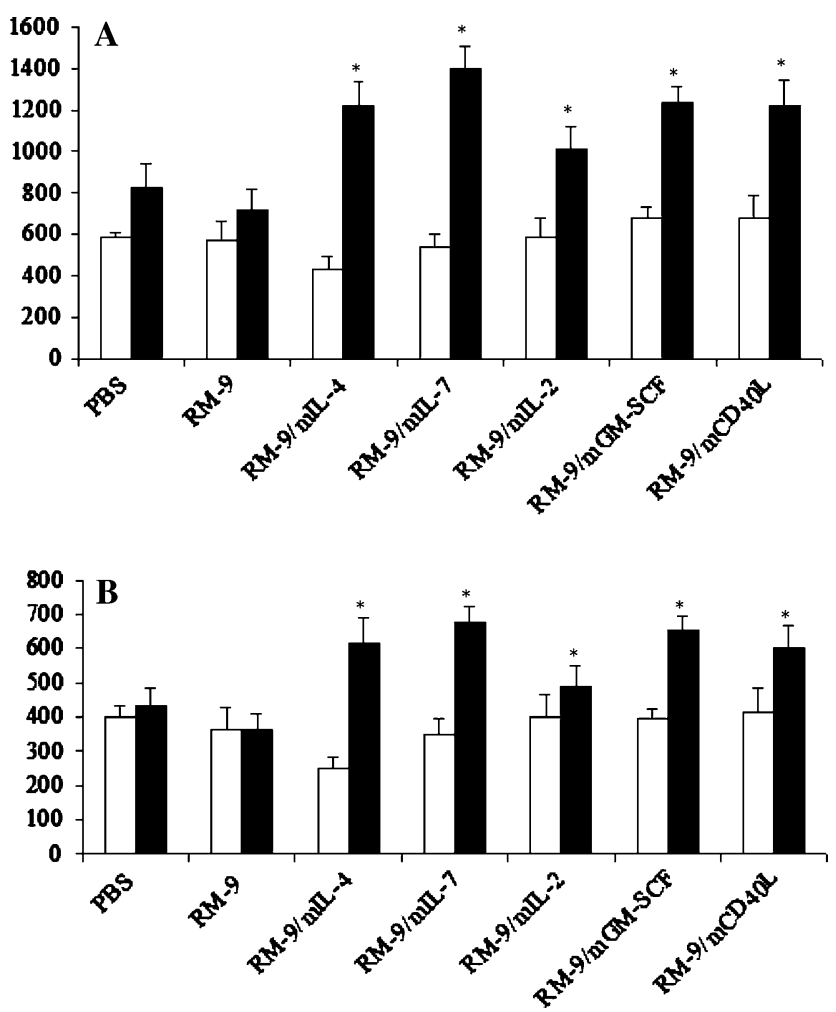

Fig. 2 The systemic response of $\mathrm{CD}^{+} / \mathrm{CD}^{+}(\mathbf{a})$ and $\mathrm{CD}^{+} / \mathrm{CD}^{+}(\mathbf{b})$ lymphocytes at $T=0$ (before vaccination) and $T=1$ (after vaccination, before challenge administration). Blood was taken via retro-orbital puncture, stained for $\mathrm{CD}^{+} / \mathrm{CD}^{+}$or $\mathrm{CD}^{+} / \mathrm{CD}^{+}$lymphocytes and were quantified by FACS analysis. The mean cell count per 10,000 cells \pm SEM is depicted $(* P<0.05$ compared to the RM-9 vaccinated group)

$\mathrm{CD}_{1} 1 \mathrm{~b}^{+}$cells were observed in all the vaccination groups throughout the tumor. T lymphocytes were mostly located at the rim of the tumor. Mice vaccinated with RM9, RM-9/mIL-2, RM-9/mIL-7, RM-9/mGM-CSF or RM-9/ mCD40L showed the highest $(\sim 5 \%) \mathrm{CD}^{+} \mathrm{T}$ lymphocyte infiltration. Cytotoxic $\mathrm{T}$ lymphocytes $\left(\mathrm{CD}^{+}\right)$were mostly observed $(\sim 5 \%)$ in tumors of mice vaccinated with RM-9/ mIL-2, RM-9/mIL-7, RM-9/mGM-CSF or RM-9/mCD40L. $\mathrm{CD} 19^{+} \mathrm{B}$ lymphocytes were only observed in tumors of mice vaccinated with RM-9/mIL-7.

Survival difference between subcutaneous and intraprostatic tumor challenge

Next, survival was determined after an intraprostatic challenge, which represents a more natural model for prostate cancer. Seven groups $(n=4)$ of mice were vaccinated with the cytokine-producing cell lines, the parental RM-9 line or PBS control, and challenged intraprostatically with the parental RM-9 cell line (Fig. 4a). No significant differences could be observed between the cytokine-producing vaccines and the RM-9 control.
The observed prolonged survival of vaccinated mice against the subcutaneous tumor challenge of the RM-9 parental cell line was no longer observed when the same tumor challenge was administered intraprostatically. This unexpected outcome against the intraprostatic challenge might be due to differences in immune surveillance between the skin and the prostate. Therefore, a study was designed using the RM-9/mGM-CSF cell line as intraprostatic challenge. Such a tumor challenge might recruit antigen-presenting cells (APCs) into the prostate and increase immune surveillance. Four groups $(n=4)$ of mice were vaccinated with PBS or RM-9/mIL-7 cells and intraprostatically challenged with either parental RM-9 cells or RM-9/mGM-CSF cells (Fig. 4b). In the PBS vaccinated groups, challenged with either the parental RM-9 cell line or the RM-9/mGM-CSF cell line, no difference in survival was observed. Also, no difference in survival was observed when the PBS and RM-9/mIL-7 vaccination groups were challenged with the parental RM-9 cell line. However, enhanced survival and one tumor-free survivor were observed in mice vaccinated with RM-9/mIL-7 and challenged with RM-9/mGM-CSF $(P<0.05)$ compared to PBS vaccination followed by the RM-9/mGM-CSF challenge.

To determine if the observed prolonged survival of the RM-9/mIL-7 vaccinated and RM-9/mGM-CSF challenged mice was due to increased recruitment of immune cells, $\mathrm{CD}^{+}, \mathrm{CD}^{+}, \mathrm{CD} 11 \mathrm{~b}^{+}$and $\mathrm{CD} 19^{+}$cells were determined in end-point tumors (Fig. 4c). The mGM-CSF-producing tumor challenge resulted in increased numbers of CD11 $\mathrm{b}^{+}$ cells, both after PBS or RM-9/mIL-7 vaccination. RM-9/ mIL-7 vaccination resulted in higher numbers of $\mathrm{T}$ lymphocytes compared to the PBS vaccinated mice. The $\mathrm{CD}^{+} \mathrm{T}$ lymphocytes were mostly located at the rim of the RM-9 tumor, whereas in RM-9/mGM-CSF tumor tissue these cells were spread throughout the tumor.

\section{Discussion}

In the present study, a panel of cytokine-producing RM-9 cell lines was tested as vaccines. This panel of cytokines (IL-2, IL-4, IL-7, GM-CSF and CD40L) was chosen for their capabilities to induce inflammation at the vaccination site via tumor antigen uptake by antigen presenting cells (APC), presentation by MHC molecules, and co stimulation of $\mathrm{T}$ cells in local lymph nodes (also known as "antigen cross priming").

Mice vaccinated with either the RM-9/mGM-CSF or the RM-9/mIL-7 cell line and subcutaneously challenged with the parental RM-9 cell line showed increased systemic $\mathrm{CD}^{+}$and $\mathrm{CD}^{+}$lymphocyte counts and tumor-free survival. This vaccination effect was not observed when mice 
Fig. 3 Immune histochemistry of endpoint tumors (tumor $\geq 1,500 \mathrm{mg}$ ) of the different vaccination groups. Frozen sections were stained with $\mathrm{HE}$ or for $\mathrm{CD}^{+}, \mathrm{CD}^{+}$, $\mathrm{CD}_{11 b^{+}}$or $\mathrm{CD} 19^{+}$cell markers and scored three times on three different days

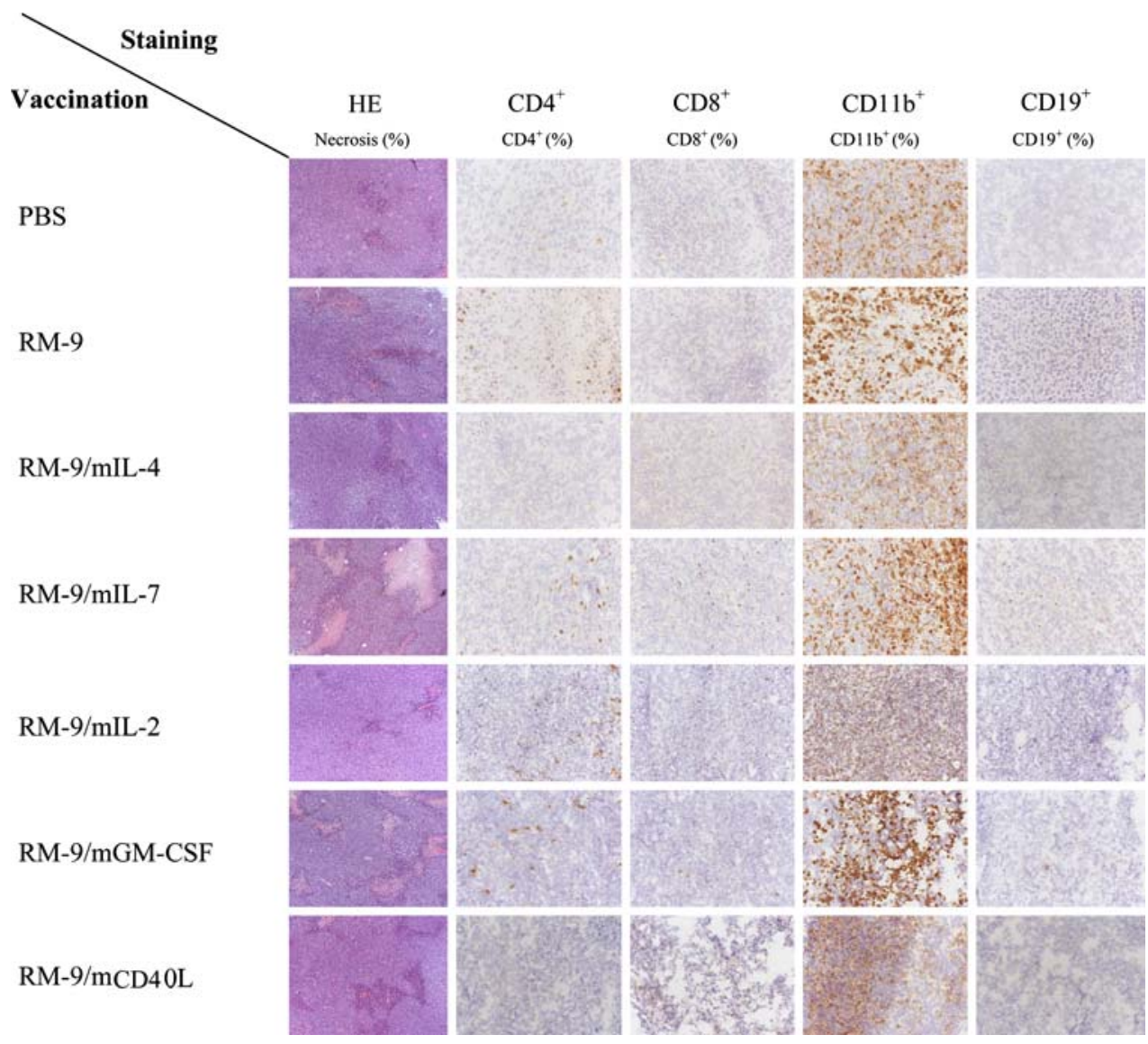

were challenged intraprostatically. Replacement of the intraprostatic challenge by the RM-9/mGM-CSF cell line restored the RM-9/mIL-7 vaccination effects.

The observed survival from a subcutaneous challenge and the immune response after RM-9/mGM-CSF vaccination were considered to be an additional effect of the secreted mGM-CSF during vaccination compared to the RM-9 control vaccination. The immunostimulatory cytokine $\mathrm{mGM}-\mathrm{CSF}$ recruits and stimulates antigen-presenting cells (APCs). When secreted during vaccination, APCs are recruited to the vaccination site. After contact of APCs with the RM-9/mGM-CSF cells, the APCs migrate to the lymph node where digested epitopes are presented to $\mathrm{T}$ lymphocytes, leading to antigen-specific activation of the $\mathrm{T}$ lymphocyte populations responsible for the desired anti-tumor immune responses. Analysis of blood from mice vaccinated with RM-9/mGM-CSF showed a significant higher increase of $\mathrm{T}$ lymphocytes compared to the control RM-9 vaccination, which might have been beneficial for tumor survival. Earlier reports on tumor cell-based vaccines, in which GMCSF secreting, irradiated tumor cells were used to generate an anti-tumor response against melanoma, cervical cancer or prostate cancer report a GM-CSF-mediated increase in T lymphocytes populations [5, 7, 30, 32]. With regard to the increased circulation of $\mathrm{T}$ lymphocytes after RM-9/mGM-
CSF vaccination it was expected that this would have an effect on the survival of these mice. Even though the prolonged survival after RM-9/mGM-CSF vaccinated mice was not significantly different compared to the RM-9 control vacation, three out of nine mice did not develop any tumor up to 125 days after tumor challenge administration. The tumors of mice that did not survive the challenge were screened for necrotic areas and immunological infiltration. Even though both $\mathrm{CD}^{+} \mathrm{T}$ lymphocytes and $\mathrm{CD} 11^{+} \mathrm{b}$ cells were detected in the end-point tumors of the RM-9 vaccination control group, the non-surviving RM-9/mGM-CSF mice also showed larger necrotic areas and an increased infiltration of $\mathrm{CD}^{+} \mathrm{T}$ lymphocytes. This would suggest that despite the fact that these mice did not survive the tumor challenge, the mGM-CSF secretion during vaccination was capable of boosting the anti-tumor response. An explanation for the difference between survivors and nonsurvivors within the RM-9/mGM-CSF group, based on circulating $\mathrm{CD}^{+}$and $\mathrm{CD}^{+} \mathrm{T}$ lymphocytes after vaccination, might be the significant increase in $\mathrm{CD}^{+}$T-lymphocytes that was detected in the survivors. A beneficial relation between GM-CSF and survival has also been reported in studies on HIV. In these studies GM-CSF was administered to HIV-infected patients, which eventually led to increased $\mathrm{CD}^{+} \mathrm{T}$ lymphocyte counts $[1,20]$. 

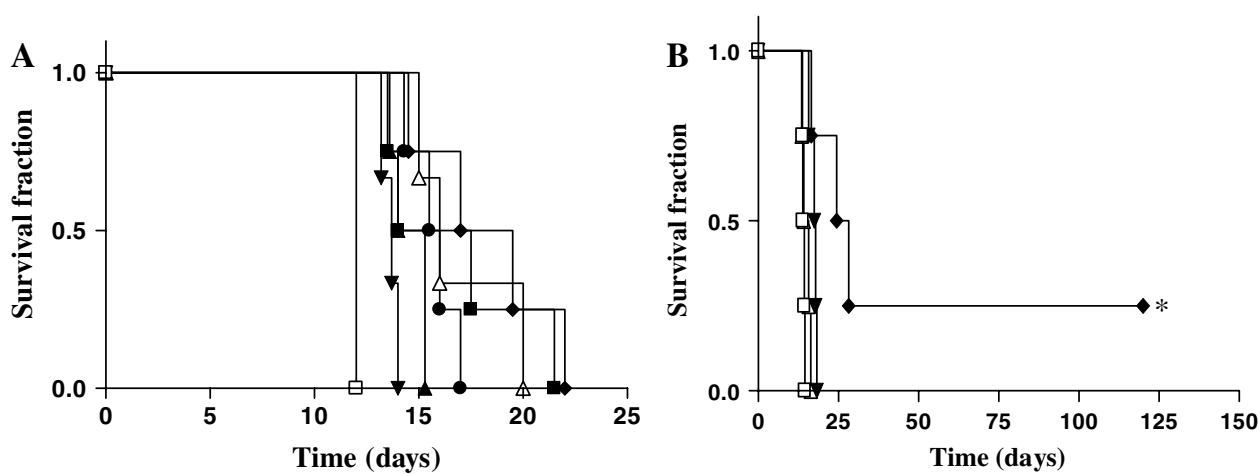

\begin{tabular}{|l|l|l|l|}
\hline Symbol & Vaccine & $\begin{array}{l}\text { Median survival } \pm \\
\text { бmed(days) }\end{array}$ & $\begin{array}{l}\text { Tumor-free } \\
\text { survival }\end{array}$ \\
\hline $\boldsymbol{\square}$ & PBS & $12.4 \pm 0.0$ & $0 / 3$ \\
\hline$\Delta$ & RM-9 & $16.6 \pm 1.6$ & $0 / 3$ \\
\hline $\boldsymbol{\nabla}$ & RM-9/mIL-2 & $16.6 \pm 0.8$ & $0 / 4$ \\
\hline $\boldsymbol{\nabla}$ & RM-9/mIL-4 & $14.0 \pm 0.3$ & $0 / 3$ \\
\hline $\boldsymbol{\nabla}$ & RM-9/mIL-7 & $18.4 \pm 2.5$ & $0 / 4$ \\
\hline $\boldsymbol{\square}$ & RM-9/mGM-CSF & $16.9 \pm 2.9$ & $0 / 4$ \\
\hline $\boldsymbol{\Delta}$ & RM-9/mCD40L & $15.0 \pm 0.6$ & $0 / 4$ \\
\hline
\end{tabular}

\begin{tabular}{|l|l|l|l|}
\hline Symbol & Vaccine $\sim$ challenge & $\begin{array}{l}\text { Median survival } \pm \\
\sigma \text { med }(\text { days })\end{array}$ & $\begin{array}{l}\text { Tumor-free } \\
\text { survival }\end{array}$ \\
\hline$\square$ & PBS $\sim$ RM-9 & $14.1 \pm 0.3$ & $0 / 4$ \\
\hline$\triangle$ & PBS $\sim$ RM-9/mGM-CSF & $15.0 \pm 0.8$ & $0 / 4$ \\
\hline$\nabla$ & RM-9/mIL-7 $\sim$ RM-9 & $17.6 \pm 1.0$ & $0 / 4$ \\
\hline$\bullet$ & RM-9/mIL-7 $\sim$ RM-9/mGM-CSF & $24.4 \pm 4.3$ & $1 / 4 *$ \\
\hline
\end{tabular}
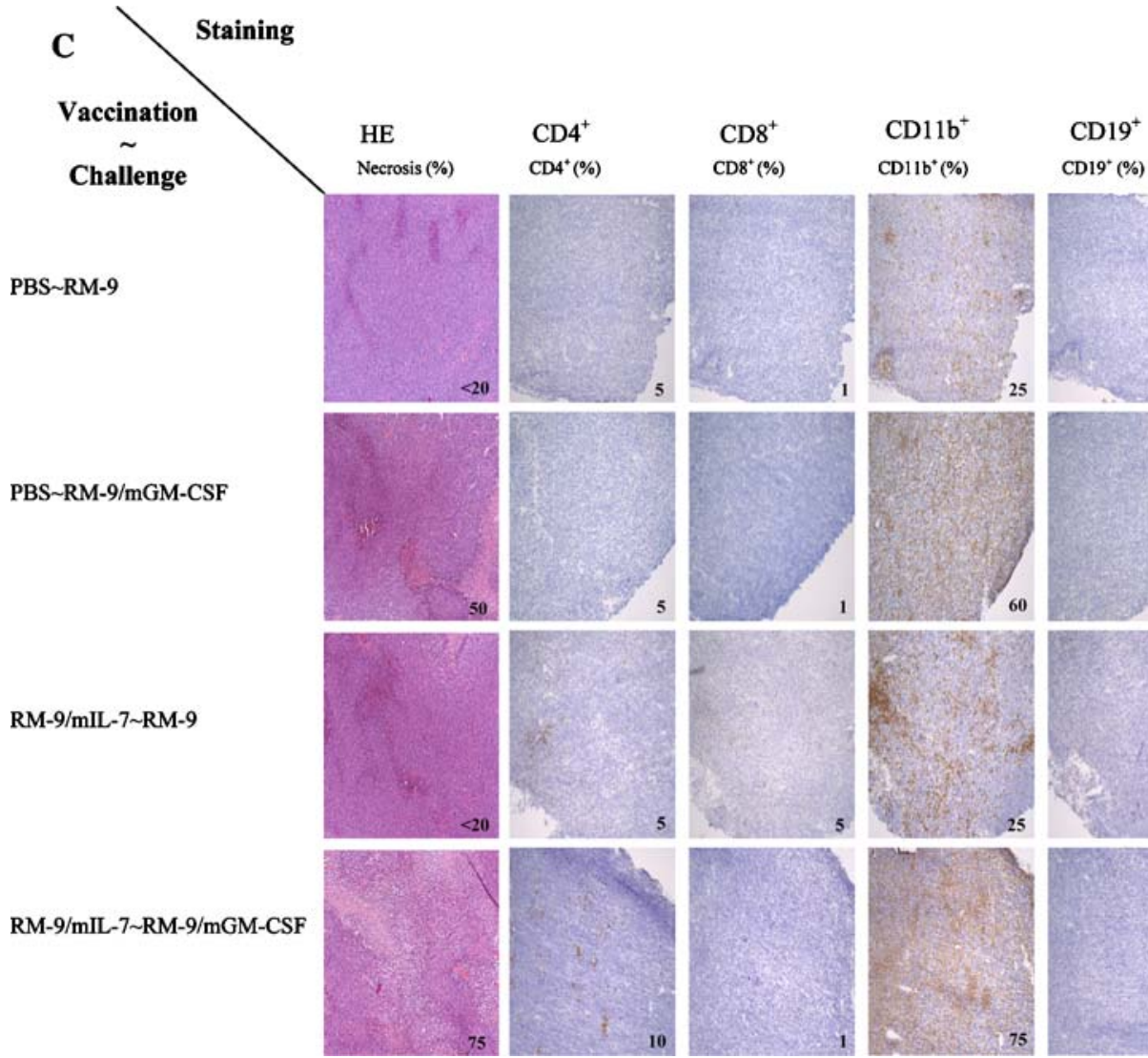

$\mathrm{CD} 19^{*}(\%)$
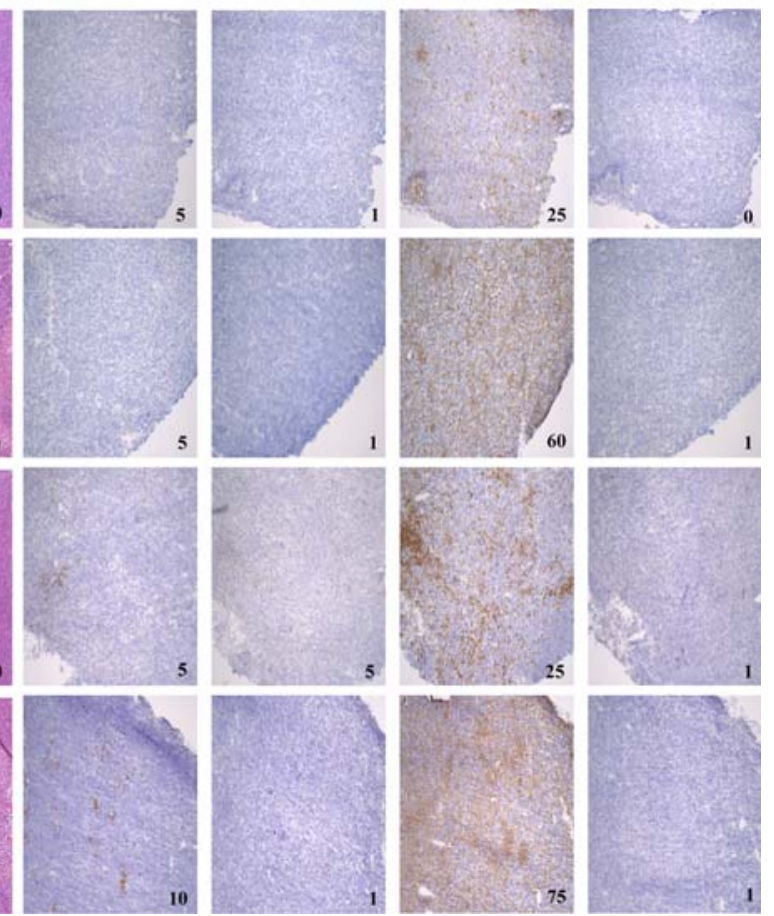

Fig. 4 Survival of vaccinated C57b1/6 mice after intraprostatic challenge. a C57bl/6 mice were subcutaneously vaccinated once a week for three consecutive weeks, followed by an intraprostatic RM-9 challenge in the fourth week and monitored for tumor development via transrectal ultrasonography $(* P<0.05$ compared to the RM-9 vaccinated mice). b C57bl/6 mice were s.c. vaccinated with PBS or RM-9/mIL-7 once a week for three consecutive weeks, followed with an intraprostatic challenge with RM-9 or RM-9/mGM-CSF in the fourth week and

was monitored for tumor development via transrectal ultrasonography and survival was determined ( $* P<0.05$ compared to RM-9/mIL-7 vaccinated mice challenged with an RM-9 challenge). c Immune histochemistry of endpoint tumors (tumor $\geq 1,000 \mathrm{mg}$ ) of mice challenged intraprostatically with either RM-9 or RM-9/mGM-CSF after vaccination with PBS or RM-9/mIL-7. Frozen sections were stained for HE or for $\mathrm{CD}^{+}, \mathrm{CD}^{+}, \mathrm{CD} 11 \mathrm{~b}^{+}$or $\mathrm{CD} 19^{+}$cell markers and scored three times on three different days 
Besides the RM-9/mGM-CSF vaccine, survival from the subcutaneous tumor challenge was also determined in the RM-9/mIL-7 vaccination group. IL-7, known as a hematopoeitic growth factor, is important for the development and survival of $\mathrm{T}$ lymphocytes, involved in the expansion of $\mathrm{T}$ cell numbers and has the ability to increase their proliferation even in the absence of activation [3, 13, 36]. In our study this effect was observed in mice that were vaccinated with the mIL-7 producing vaccine. The detected increase of circulating $\mathrm{T}$ lymphocytes was found after vaccination, this increase was even the highest increase after vaccination compared to all the other tested vaccines. It was hypothesized that epitopes of the RM-9/mIL-7 vaccine were picked up by the already present APCs at the vaccination site, which were presented to the lymphocytes in the lymph nodes. But also lymphocytes present at the vaccination site might be stimulated in development and survival due to the secreted mIL-7. With the knowledge of the increased circulation of $\mathrm{T}$ lymphocytes after vaccination, a prolonged or even tumor-free survival was expected of the mice vaccinated with RM-9/mIL-7. This expectation was confirmed with a significant longer survival compared to the RM-9 vaccination control group, and four out of the 9 mice remained tumor-free 125 days after challenge administration. Even though five mice did not survive the tumor challenge, examination of their tumors revealed increased numbers of $\mathrm{CD}^{+}$and $\mathrm{CD} 19^{+}$cells and larger necrotic areas. The presence of both $\mathrm{CD} 4^{+}$and $\mathrm{CD} 19^{+}$lymphocytes in these end-point tumors might involve an antibodydependent cell-mediated cytotoxicity of the tumor tissue. Therefore it was assumed that tumor immunity must not entirely rely on direct tumor cell killing [28]. Comparison within the RM-9/mIL-7 vaccination group revealed significant lower $\mathrm{CD}^{+} \mathrm{T}$ lymphocyte numbers in the tumor survivors compared to the non-survivors, while $\mathrm{CD}^{+}{ }^{+} \mathrm{T}$ lymphocyte numbers did not differ. It has been described that IL-7 is able to alter the $\mathrm{CD} 4^{+}: \mathrm{CD} 8^{+}$lymphocyte ratio, which could explain our observation. However, our significantly decrease of $\mathrm{CD} 8^{+}$cells in tumor surviving mice after vaccination, in our model, is in contradiction with the reported $\mathrm{CD}^{+}$lymphocyte increase after IL-7 administration [13]. Moreover, studies on IL-7 mediated tumorsuppression $[16,17]$ indicate the importance of $\mathrm{CD}^{+} \mathrm{T}$ lymphocyte recruitment, whereas $\mathrm{CD} 8^{+} \mathrm{T}$ lymphocytes were not related to IL-7-mediated tumor-suppression.

The presence of circulating $\mathrm{CD} 4^{+} \mathrm{CD} 25^{\text {high }} \mathrm{FoxP}^{+}$regulatory $\mathrm{T}$ cells (Tregs) in mice before and after administration of the subcutaneous challenge was determined in a small number of blood samples. Only low numbers of Tregs could be detected and, therefore, it was decided not to examine circulating Tregs in this study. However, Tregs might certainly be associated with $\mathrm{T}$ lymphocyte effector functions. Recently, the presence of Tregs has been associ- ated with prostate cancer [38]. On the other hand in a mouse prostate cancer model, Tregs were mentioned to be common to sites of ongoing immune responses, and to be dispensable for the induction of tumor-specific tolerance [6].

Both the vaccinations with either RM-9/mGM-CSF, or RM-9/mIL-7 were beneficial for survival from the administered subcutaneous tumor cell challenge. However, the anti-tumor effects were more evident for a subcutaneous challenge than for an intraprostatic challenge. Since immune surveillance in the skin is expected to be far better than in the prostate, the intraprostatic RM-9 cell challenge was replaced by an intraprostatic RM-9/mGM-CSF cell challenge. It was hypothesised that mGM-CSF secretion by the tumor could increase its surveillance. Production of mGM-CSF by the intraprostatic tumor stimulated CD11 $\mathrm{b}^{+}$ cell infiltration when compared to the parental RM-9 tumor challenge. This infiltration was assumed to increase the immune surveillance of the prostate, which in its turn might be beneficial for an anti-tumor response evoked by vaccination. This was confirmed when a combination of RM-9/ mGM-CSF tumor challenge and RM-9/mIL-7 vaccination resulted in larger necrotic areas in the tumor, increased

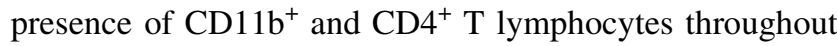
the tumor challenge, and significantly prolonged survival compared to RM-9/mIL-7 vaccinated mice which received a RM-9 tumor challenge. The increased presence of $\mathrm{CD} 11 \mathrm{~b}+$ was assumed to be the effect of the RM-9/mGM$\mathrm{CSF}$ tumor. The $\mathrm{CD} 4^{+}$lymphocyte infiltration throughout the tumor, together with the larger necrotic areas, was related to the mIL-7 production by vaccine. This vaccination effect was no longer detectible when the tumor challenge was administered intraprostatically. But, the combination of the mIL-7 vaccination with an intraprostatic mGM-CSF producing tumor challenge partly restored the vaccination effect and it was assumed that the observed protection could be found in the difference in infiltration of $\mathrm{CD} 4^{+}$cells Despite the fact that some RM-9/mIL-7 vaccinated mice did not survive the intraprostatic tumor challenge, immune histochemistry of these tumors showed a $\mathrm{CD} 4^{+}$lymphocyte infiltration at the rim of the tumor in case of an RM-9 tumor challenge, whereas tumors of the RM-9/mGM-CSF challenge showed $\mathrm{CD} 4^{+}$lymphocyte infiltration throughout the tumor. This infiltration of $\mathrm{CD}^{+}$lymphocytes throughout the tumor was assumed to be the effect of the increased $\mathrm{CD}_{1} 1^{+}$cells that were detected in the RM-9/ mGM-CSF tumors. Altogether, this could explain the larger necrotic areas found in these tumors and the survival $[2,5,7,30-32]$.

Furthermore, the observed difference in survival between the subcutaneous and the intraprostatic challenge could also be an effect of a blood-prostate-barrier, which is assumed to restrict the passage of leukocytes for immune 
surveillance of the prostate $[9,12,23]$. By using an immunological attractant like GM-CSF this barrier might be broken, making the prostate better accessible. Also, recent investigation on administration of human IL-7 in combination with GM-CSF secreting tumor cells, confirmed the possible immunological benefit of the combination of IL-7 and GM-CSF [24]. This study showed for melanoma that IL-7, when combined with GM-CSF secreting tumor cell immunotherapy, significantly prolonged the survival of the tumor bearing mice. This enhanced anti-tumor protection was correlated with an increased number of activated dendritic cells and T lymphocytes in lymphoid tissue.

\section{Conclusion}

Murine IL-7 and mGM-CSF expressed during vaccination with a whole cell vaccine resulted in an additional immunological protection, compared to the RM-9 control vaccination, against a subcutaneously and an intraprostatically administered RM-9 cell challenge. This enhanced protection was more evident in the skin than in the prostate. The prostate, which is assumed to restrict the passage of leukocytes for immune surveillance of the prostate, seems to be better accessible with an immunological attractant like GM-CSF. Furthermore, tumor immunity must not entirely rely on direct tumor cell killing but in our model it seems to be a combination of APCs and $\mathrm{CD} 4^{+}$lymphocytes.

Acknowledgments The authors thank Dr. T.C. Thompson for providing the mouse prostate reconstitution model, and they also thank Drs. R.A. Willemsen and E.A.M. Schenk for critical reading.

Open Access This article is distributed under the terms of the Creative Commons Attribution Noncommercial License which permits any noncommercial use, distribution, and reproduction in any medium, provided the original author(s) and source are credited.

\section{References}

1. Angel JB, High K, Rhame F, Brand D, Whitmore JB, Agosti JM, Gilbert MJ, Deresinski S (2000) Phase III study of granulocytemacrophage colony-stimulating factor in advanced HIV disease: effect on infections, CD4 cell counts and HIV suppression. Leukine/HIV Study Group. Aids 14(4):387-395

2. Armant M, Delespesse G, Sarfati M (1995) IL-2 and IL-7 but not IL-12 protect natural killer cells from death by apoptosis and upregulate bcl-2 expression. Immunology 85(2):331-337

3. Aspinall R, Henson S, Pido-Lopez J, Ngom PT (2004) Interleukin7: an interleukin for rejuvenating the immune system. Ann N Y Acad Sci 1019:116-122

4. Blankenstein T, Rowley DA, Schreiber H (1991) Cytokines and cancer: experimental systems. Curr Opin Immunol 3(5):694-698

5. Chang EY, Chen CH, Ji H, Wang TL, Hung K, Lee BP, Huang AY, Kurman RJ, Pardoll DM, Wu T (2000) Antigen-specific cancer immunotherapy using a GM-CSF secreting allogeneic tumor cell-based vaccine. Int J Cancer 86(5):725-730
6. Degl'Innocenti E, Grioni M, Capuano G, Jachetti E, Freschi M, Bertilaccio MT, Hess-Michelini R, Doglioni C, Bellone M (2008) Peripheral T-cell tolerance associated with prostate cancer is independent from $\mathrm{CD} 4{ }^{+} \mathrm{CD} 25^{+}$regulatory $\mathrm{T}$ cells. Cancer Res 68(1):292-300

7. Dranoff G, Jaffee E, Lazenby A, Golumbek P, Levitsky H, Brose K, Jackson V, Hamada H, Pardoll D, Mulligan RC (1993) Vaccination with irradiated tumor cells engineered to secrete murine granulocyte-macrophage colony-stimulating factor stimulates potent, specific, and long-lasting anti-tumor immunity. Proc Natl Acad Sci USA 90(8):3539-3543

8. Dreno B, Nguyen JM, Khammari A, Pandolfino MC, Tessier MH, Bercegeay S, Cassidanius A, Lemarre P, Billaudel S, Labarriere N, Jotereau F (2002) Randomized trial of adoptive transfer of melanoma tumor-infiltrating lymphocytes as adjuvant therapy for stage III melanoma. Cancer Immunol Immunother 51(10):539-546

9. El-Alfy M, Pelletier G, Hermo LS, Labrie F (2000) Unique features of the basal cells of human prostate epithelium. Microsc Res Tech 51(5):436-446

10. Fearon ER, Pardoll DM, Itaya T, Golumbek P, Levitsky HI, Simons JW, Karasuyama H, Vogelstein B, Frost P (1990) Interleukin-2 production by tumor cells bypasses $\mathrm{T}$ helper function in the generation of an antitumor response. Cell 60(3):397-403

11. Ferlay J, Bray F, Pisani P, Parkin DM (2004) GLOBOCAN 2002: cancer incidence, mortality and prevalence worldwide. IARC CancerBase No. 5. version 2.0, IARC Press, Lyon

12. Fulmer BR, Turner TT (2000) A blood-prostate barrier restricts cell and molecular movement across the rat ventral prostate epithelium. J Urol 163(5):1591-1594

13. Geiselhart LA, Humphries CA, Gregorio TA, Mou S, Subleski J, Komschlies KL (2001) IL-7 administration alters the CD4:CD8 ratio, increases $\mathrm{T}$ cell numbers, and increases $\mathrm{T}$ cell function in the absence of activation. J Immunol 166(5):3019-3027

14. Gilboa E, Lyerly HK, Vieweg J, Saito S (1994) Immunotherapy of cancer using cytokine gene-modified tumor vaccines. Semin Cancer Biol 5(6):409-417

15. Hall SJ, Thompson TC (1997) Spontaneous but not experimental metastatic activities differentiate primary tumor-derived vs metastasis-derived mouse prostate cancer cell lines. Clin Exp Metastasis 15(6):630-638

16. Hock H, Dorsch M, Diamantstein T, Blankenstein T (1991) Interleukin 7 induces $\mathrm{CD}^{+} \mathrm{T}$ cell-dependent tumor rejection. J Exp Med 174(6):1291-1298

17. Hock H, Dorsch M, Kunzendorf U, Qin Z, Diamantstein T, Blankenstein T (1993) Mechanisms of rejection induced by tumor celltargeted gene transfer of interleukin 2, interleukin 4, interleukin 7, tumor necrosis factor, or interferon gamma. Proc Natl Acad Sci USA 90(7):2774-2778

18. Hoption Cann SA, van Netten JP, van Netten C, Glover DW (2002) Spontaneous regression: a hidden treasure buried in time. Med Hypotheses 58(2):115-119

19. Hull GW, McCurdy MA, Nasu Y, Bangma CH, Yang G, Shimura S, Lee HM, Wang J, Albani J, Ebara S, Sato T, Timme TL, Thompson TC (2000) Prostate cancer gene therapy: comparison of adenovirus-mediated expression of interleukin 12 with interleukin 12 plus B7-1 for in situ gene therapy and gene-modified, cellbased vaccines. Clin Cancer Res 6(10):4101-4109

20. Jacobson JM, Lederman MM, Spritzler J, Valdez H, Tebas P, Skowron G, Wang R, Jackson JB, Fox L, Landay A, Gilbert MJ, O’Neil D, Bancroft L, Al-Harthi L, Jacobson MA, Merigan TC Jr, Glesby MJ (2003) Granulocyte-macrophage colony-stimulating factor induces modest increases in plasma human immunodeficiency virus (HIV) type 1 RNA levels and $\mathrm{CD}^{+}$lymphocyte counts in patients with uncontrolled HIV infection. J Infect Dis 188(12):1804-1814 
21. Kraaij R, van Weerden WM, de Ridder CM, Gussenhoven EJ, Honkoop J, Nasu Y, Bangma CH (2002) Validation of transrectal ultrasonographic volumetry for orthotopic prostate tumours in mice. Lab Anim 36(2):165-172

22. Lasek W, Basak G, Switaj T, Jakubowska AB, Wysocki PJ, Mackiewicz A, Drela N, Jalili A, Kaminski R, Kozar K, Jakobisiak M (2004) Complete tumour regressions induced by vaccination with IL-12 gene-transduced tumour cells in combination with IL-15 in a melanoma model in mice. Cancer Immunol Immunother 53(4):363-372

23. Leibovitz A, Baumoehl Y, Segal R (2004) Increased incidence of pathological and clinical prostate cancer with age: age related alterations of local immune surveillance. J Urol 172(2):435-437

24. Li B, Vanroey MJ, Jooss K (2007) Recombinant IL-7 enhances the potency of GM-CSF-secreting tumor cell immunotherapy. Clin Immunol 123(2):155-165

25. Liyanage UK, Moore TT, Joo HG, Tanaka Y, Herrmann V, Doherty G, Drebin JA, Strasberg SM, Eberlein TJ, Goedegebuure PS, Linehan DC (2002) Prevalence of regulatory T cells is increased in peripheral blood and tumor microenvironment of patients with pancreas or breast adenocarcinoma. J Immunol 169(5):2756-2761

26. Marincola FM, Wang E, Herlyn M, Seliger B, Ferrone S (2003) Tumors as elusive targets of T-cell-based active immunotherapy. Trends Immunol 24(6):335-342

27. Mishra D, Mishra PK, Dubey V, Dabadghao S, Jain NK (2007) Evaluation of uptake and generation of immune response by murine dendritic cells pulsed with hepatitis B surface antigen-loaded elastic liposomes. Vaccine 25(39-40):6939-6944

28. Qin Z, Blankenstein T (2000) $\mathrm{CD}^{+} \mathrm{T}$ cell-mediated tumor rejection involves inhibition of angiogenesis that is dependent on IFN gamma receptor expression by nonhematopoietic cells. Immunity 12(6):677-686

29. Rembrink K, Romijn JC, van der Kwast TH, Rubben H, Schroder FH (1997) Orthotopic implantation of human prostate cancer cell lines: a clinically relevant animal model for metastatic prostate cancer. Prostate 31(3):168-174

30. Simons JW, Mikhak B, Chang JF, DeMarzo AM, Carducci MA, Lim M, Weber CE, Baccala AA, Goemann MA, Clift SM, Ando DG, Levitsky HI, Cohen LK, Sanda MG, Mulligan RC, Partin AW, Carter HB, Piantadosi S, Marshall FF, Nelson WG (1999) Induction of immunity to prostate cancer antigens: results of a clinical trial of vaccination with irradiated autologous prostate tumor cells engineered to secrete granulocyte-macrophage colonystimulating factor using ex vivo gene transfer. Cancer Res 59(20):5160-5168

31. Smyth MJ, Nutt SL (2006) IL-7 and the thymus dictate the NK cell 'labor market'. Nat Immunol 7(11):1134-1136

32. Soiffer R, Hodi FS, Haluska F, Jung K, Gillessen S, Singer S, Tanabe K, Duda R, Mentzer S, Jaklitsch M, Bueno R, Clift S, Hardy S, Neuberg D, Mulligan R, Webb I, Mihm M, Dranoff G (2003) Vaccination with irradiated, autologous melanoma cells engineered to secrete granulocyte-macrophage colony-stimulating factor by adenoviral-mediated gene transfer augments antitumor immunity in patients with metastatic melanoma. J Clin Oncol 21(17):3343-3350

33. Somasundaram R, Jacob L, Swoboda R, Caputo L, Song H, Basak S, Monos D, Peritt D, Marincola F, Cai D, Birebent B, Bloome E, Kim J, Berencsi K, Mastrangelo M, Herlyn D (2002) Inhibition of cytolytic $\mathrm{T}$ lymphocyte proliferation by autologous $\mathrm{CD}_{4}^{+} /$ $\mathrm{CD} 25^{+}$regulatory T cells in a colorectal carcinoma patient is mediated by transforming growth factor-beta. Cancer Res 62(18):52675272

34. Todryk SM, Birchall LJ, Erlich R, Halanek N, Orleans-Lindsay JK, Dalgleish AG (2001) Efficacy of cytokine gene transfection may differ for autologous and allogeneic tumour cell vaccines. Immunology 102(2):190-198

35. Weber CE (1998) Cytokine-modified tumor vaccines: an antitumor strategy revisited in the age of molecular medicine. Cancer Nurs 21(3): 167-177

36. Westermann J, Aicher A, Qin Z, Cayeux Z, Daemen K, Blankenstein T, Dorken B, Pezzutto A (1998) Retroviral interleukin-7 gene transfer into human dendritic cells enhances $\mathrm{T}$ cell activation. Gene Ther 5(2):264-271

37. Wiemann B, Starnes CO (1994) Coley's toxins, tumor necrosis factor and cancer research: a historical perspective. Pharmacol Ther 64(3):529-564

38. Yokokawa J, Cereda V, Remondo C, Gulley JL, Arlen PM, Schlom J, Tsang KY (2008) Enhanced functionality of $\mathrm{CD} 4^{+} \mathrm{CD} 25$ (high)FoxP $3^{+}$regulatory $\mathrm{T}$ cells in the peripheral blood of patients with prostate cancer. Clin Cancer Res 14(4):1032-1040 